\title{
Shear behavior of the interface between drilling equipments and shale rocks
}

\author{
F. L. Pellet $\cdot$ M. Keshavarz
}

Received: 20 August 2013/Accepted: 5 February 2014/Published online: 26 February 2014

(C) The Author(s) 2014. This article is published with open access at Springerlink.com

\begin{abstract}
Drilling operations in a borehole can lead to problems when the friction between the drilling equipments and the host rock are not well identified. This paper reports an experimental program carried out to characterize the shear behavior of an interface between a shale rock and the steel parts of the drilling equipment (bottom hole assembly and casing). Direct shear tests were performed with an advanced shear box, on interfaces made up of shale specimens and steel plates both in natural and water re-saturated conditions. The shear tests were performed at different normal stress levels from 2 to $12 \mathrm{MPa}$ and the results show that the shear stress increases when the normal stress is increased. While the cohesion strength between the steel plate and shale is almost zero in a dry condition, this parameter reaches about $1 \mathrm{MPa}$ in the presence of water. The average friction coefficient is determined to be 0.45 in the dry condition and it decreases to 0.21 when water is present. These findings should allow engineers involved in drilling operations and casing installation to assess more accurately the forces required to pull tools out of the borehole when problems arise. Therefore, this information could help to mitigate the risks encountered during well drilling.
\end{abstract}

Keywords Geomechanics - Shale · Drilling · Casing · Friction

\section{F. L. Pellet $(\bowtie)$}

Department of Civil and Environmental Engineering,

INSA-University of Lyon, Villeurbanne, France

e-mail: frederic.pellet@cfmr-roches.org

\section{Keshavarz}

Faculty of Science, University of Payam Nour, Zanjan, Iran

M. Keshavarz

Joseph Fourier University, Grenoble, France

\section{Introduction}

Drilling deep boreholes in shale formations can be difficult, especially when the borehole deviates. In such a situation, frictional forces between the drilling equipments (bottom hole assembly and casing) and the host rock mass can be very high and the drilling tools can be easily stuck (Azar 2006; Fontoura et al. 2012; Padma Raju and Kumara Swany 2012). The installation of casing strings can also be complicated in such conditions and the risk of encountering problems is high (Mason et al. 2000; Sanchez and Al-Harthy 2011).

In order to prevent such problems, a comprehensive understanding of the mechanical behavior of the contact between the steel parts (bottom hole assembly and casing) and the host formation is required. Some authors proposed experimental procedures to determine the friction coefficient (Maidla and Wojtanowicz 1990) while other authors focused on modeling to allow the assessment of force and torque for running casing (Lagreca et al. 1997; Castelletto et al. 2010; Mirhaj et al. 2011).

For the purpose of a better assessment of the shear strength (friction coefficient and cohesion), a testing program was carried out; this consisted of unidirectional shear tests performed using an advanced shear equipment (Boulon 1995) to characterize the shear strength and shear deformability properties of the steel-rock interface. Normal stress acting perpendicularly to the slipping surface is varied to reproduce different horizontal stress conditions in term of maximum and minimum horizontal stress $\left(\mathrm{Sh}_{\min }\right.$ and $\left.\mathrm{SH}_{\mathrm{Max}}\right)$.

\section{Rock under study}

Problematic rocks encountered in drilling operations are often sedimentary rocks such as shale or more generally

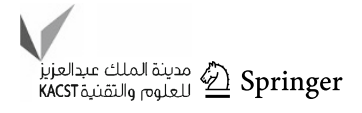


Table 1 Rock properties

\begin{tabular}{llllll}
\hline $\begin{array}{l}\text { Density } \\
\mathrm{kN} / \mathrm{m}^{3}\end{array}$ & $\begin{array}{l}\text { Water } \\
\text { content } \\
(\%)\end{array}$ & $\begin{array}{l}\text { Porosity } \\
(\%)\end{array}$ & $\begin{array}{l}\text { Saturation } \\
\text { degree } \\
(\%)\end{array}$ & $\begin{array}{l}\text { P-wave } \\
\text { velocity } \\
(\mathrm{m} / \mathrm{s})\end{array}$ & $\begin{array}{l}\text { UCS } \\
(\mathrm{MPa})\end{array}$ \\
\hline 23.7 & 5.9 & 15.5 & 87 & 4,200 & 26 \\
\hline
\end{tabular}

claystone and siltstone. Because of their mineralogy, sedimentary rocks are often classified by the predominant grain size of their constituent minerals (e.g., clay minerals, carbonates or quartz) and other textural features such as layering. Claystone is a compact rock that is derived from mudstone and has undergone a higher degree of lithification than shale, but is less clearly laminated. These rocks, which constitute the cap rock layer in many oil fields, play an important role in carbon dioxide sequestration sites to prevent gas leakage from reservoirs.

In shale formations, wellbore stability problems are caused often due to the presence of water (Rojas et al. 2006). Furthermore, the swelling properties of shale can complicate drilling operations even more.

The tests presented in this study were performed on shale from the Dogger epoch. This rock is roughly made up of $50 \%$ clay, $30 \%$ carbonate and $20 \%$ quartz. The clay is mostly illite with some smectite. Because clay minerals are sensitive to water, special attention has been paid to characterize the behavior of the shale with a natural water content to account for in situ conditions; the natural water content of the rock specimens lies between 4 and $7 \%$.

The mechanical properties of this shale, including timedependent properties (Table 1), have been investigated by several authors (Fabre and Pellet 2006; Pellet and Fabre 2007). Shrinkage and swelling characteristics as well as hydro-mechanical properties and permeability have been also investigated intensively (Cariou et al. 2009; Buzzi et al. 2007). However, the mechanical behavior of the rock under direct shear has not been recently investigated (Pellet et al. 2013).

\section{Testing equipment and testing program}

\section{Testing equipment}

The shearing device used for this testing program is a $3 \mathrm{D}$ shear box (Fig. 1) originally developed by Boulon (1995). This equipment allows the control of stresses and displacements in the three spatial directions; consequently, it is possible to shear rock discontinuities in the two horizontal directions. Moreover, the displacement and the force generated in the third direction (i.e. vertical direction) can be servo-controlled (Pellet et al. 2013). Therefore, tests can

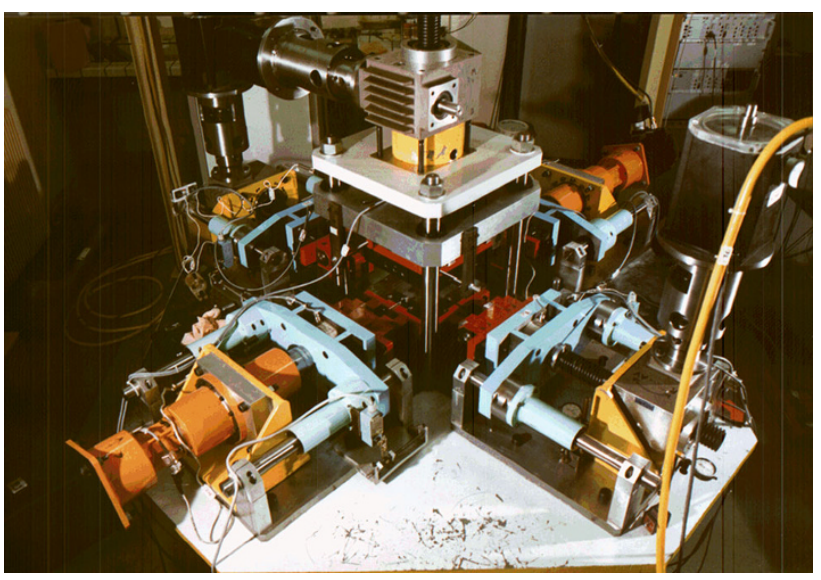

Fig. 1 View of the testing equipment

be performed with a constant normal stiffness or zero volume change by controlling the interface dilation. Additionally, it is also possible to carry out shear tests under cyclic loadings (Jafari et al. 2003).

The originality of this equipment is that during shearing, the two halves of the sample box can move simultaneously in opposite directions. Hence, the normal force remains centered on the sheared surface throughout the whole shearing process and no rotation of the half boxes occurs.

More recently, this equipment was modified to study the hydro-mechanical behavior of rock discontinuities. This improvement consists of a hole made in the center of the lower half box, which allows fluid to be injected into the interface region to simulate in situ conditions and, therefore, is able to account for coupled hydro-mechanical behavior (Hans and Boulon 2003).

\section{Specimen preparation and material characterization}

Direct shear test were performed on discontinuities made up of a steel part and a shale specimen. The upper box contained the shale specimen and the lower box was made of steel. After coring, rock specimens were carefully sealed and were cut just before testing. Figure 2 shows the two parts of the test body (steel plate and rock specimen) before and after assembly, prior to testing.

The steel used to make the lower half box was a raw rolling product commercially available with a roughness characterized by a maximum height of $0.05 \mathrm{~mm}$.

Prior to testing, the rock specimens were embedded and fixed into the upper half box with a grout made up of a mixture of fast-curing cement and Vicat ordinary cement. The optimal ratio (75\% fine sand, $25 \%$ cement) was determined to obtain the maximum strength at a minimum curing time. The ratio of mass of water to mass of cementaggregate $(\mathrm{E} / \mathrm{C})$ was 0.15 . Rock specimens were directly set and fixed with this cement mixture in the steel boxes. 
Fig. 2 Photos of the two half boxes: a half boxes open showing the rock specimen on the left-hand side and the steel plate on the right-hand side with a hole in the center for water injection. b Steel plate (bottom part) and rock specimen (upper part) are assembled ready to be installed in the shear apparatus
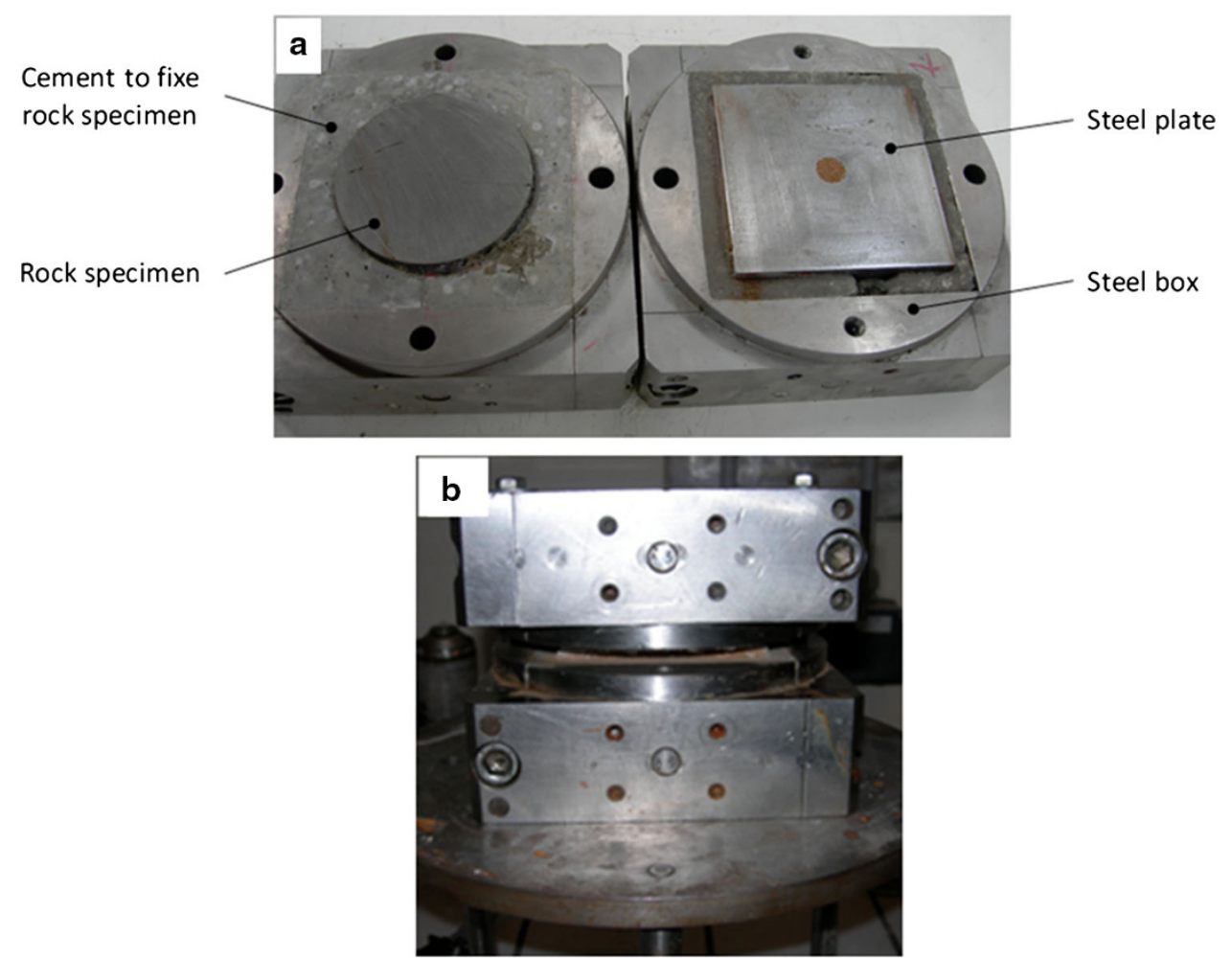

\section{Test results and discussion}

Table 2 Test conditions

\begin{tabular}{lll}
\hline Test & Interface condition & Testing condition \\
\hline TD-CNL-08 & Dry & CNL \\
TW-CNL-09 & Wet & CNL \\
TD-CNL-10 & Dry & CNL \\
TW-CNL-11 & Wet & CNL \\
TD-CNL-12 & Dry & CNL \\
TW-CNL-13 & Wet & CNL \\
TD-CNL-14 & Dry & CNL \\
TW-CNL-15 & Wet & CNL \\
TD-CNL-16 & Dry & CNL \\
TD-CV-18 & Dry & CV \\
TW-CV-20 & Wet & CV \\
TW-CV-22 & Wet & CV \\
\hline
\end{tabular}

$C N L$ constant normal load, $C V$ constant volume

Testing program

The shear test program included a series of tests performed on discontinuities under two different conditions: the first was a dry condition and the second was fresh water saturated. For these two conditions, tests were performed either with a constant normal load (CNL), or a constant volume (CV). Table 2 summarizes the testing program. Overall, 12 shear tests were performed.
Test results were analyzed with the help of three graphs representing, respectively, shear stress versus shear displacement, normal stress versus normal displacement and shear displacement versus normal displacement (Fig. 3). The mobilized friction as a function of shear displacement was also calculated and plotted. The mobilized friction is the ratio of the shear stress divided by the normal stress which acts perpendicularly to the interface.

For an applied normal stress, shear displacement increases until the maximum shear stress is reached. At every $2 \mathrm{~mm}$, the normal stress was increased to the next stage and the shearing process was resumed. At the end of the actuator stroke, the shearing direction was reversed and shearing performed in the opposite direction for $12 \mathrm{~mm}$.

By analyzing, the shear stress-shear displacement curve (Fig. 3a) the shear strength and shear stiffness could be determined. Normal stiffness was computed from the curve of the normal stress versus normal displacement (Fig. 3b). In addition, the dilation or contraction of the interface could be determined from the curve of the shear displacement versus normal displacement (Fig. 3c).

In the next section we analyze the three curves for each test. 

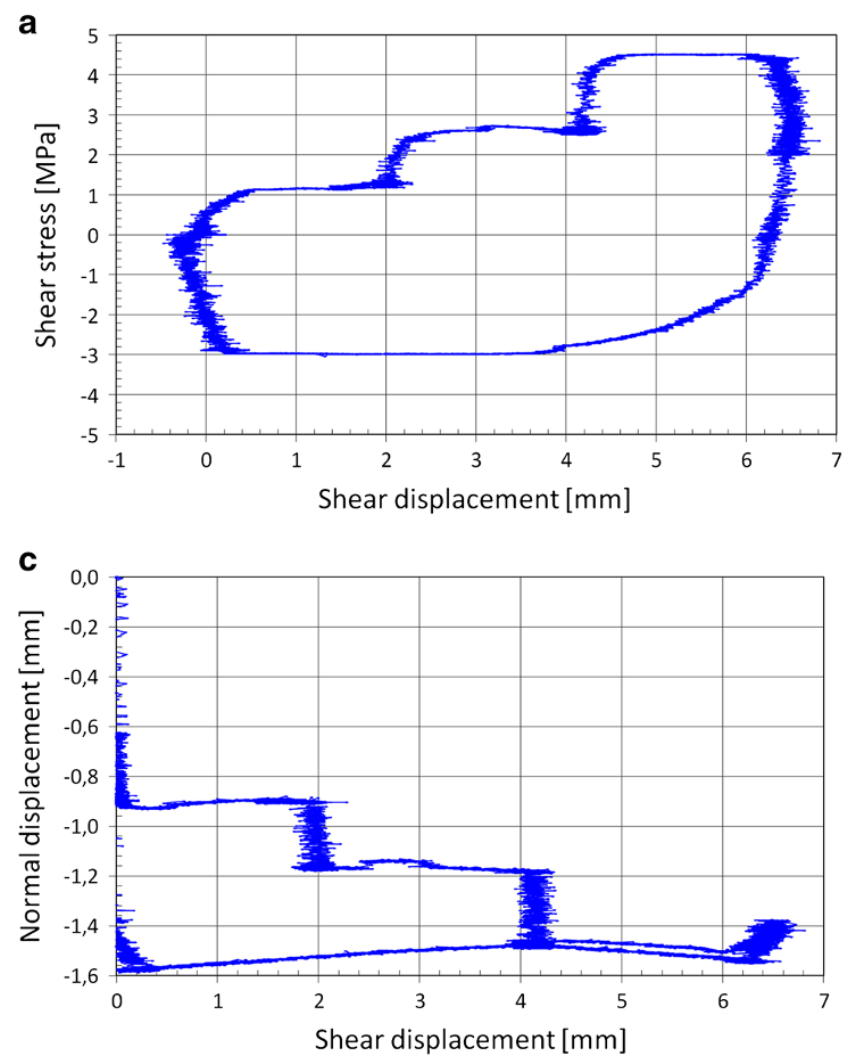

Fig. 3 Shear test TD-CNL-12 performed on dry shale-steel interface under constant normal load CNL (5, 10 and $12 \mathrm{MPa}$ ): a shear stress versus shear displacement, b normal stress versus normal

Direct shear tests on a dry shale-steel interface

\section{Shearing at a constant normal load (CNL tests)}

The first series of tests was conducted on dry steel-shale interfaces tested at three different normal stresses (2, 5 and $12 \mathrm{MPa}$ ). These stress levels were chosen to avoid damage to the rock matrix during the shear tests to obtain reliable results. During this test, the normal stress was kept constant. Figure 3 shows the typical behavior of this interface for the three levels of normal stress (TD-CNL-12).

The specimen was first slightly compressed to ensure that the two parts of the specimen walls were well positioned (Fig. 3b). The normal stress was then increased to $2 \mathrm{MPa}$ and the specimen sheared up to $2 \mathrm{~mm}$. The test continued with normal stresses of 5 and $12 \mathrm{MPa}$. For each stage of normal stress the shearing displacement was $2 \mathrm{~mm}$. Once the final shearing was achieved under a normal stress of $12 \mathrm{MPa}$, the shear direction was reversed (Fig. 3a).

For each stage of normal stress, it was observed that during shearing the shear stress increased rapidly to reach a maximum value and then remained almost constant. b
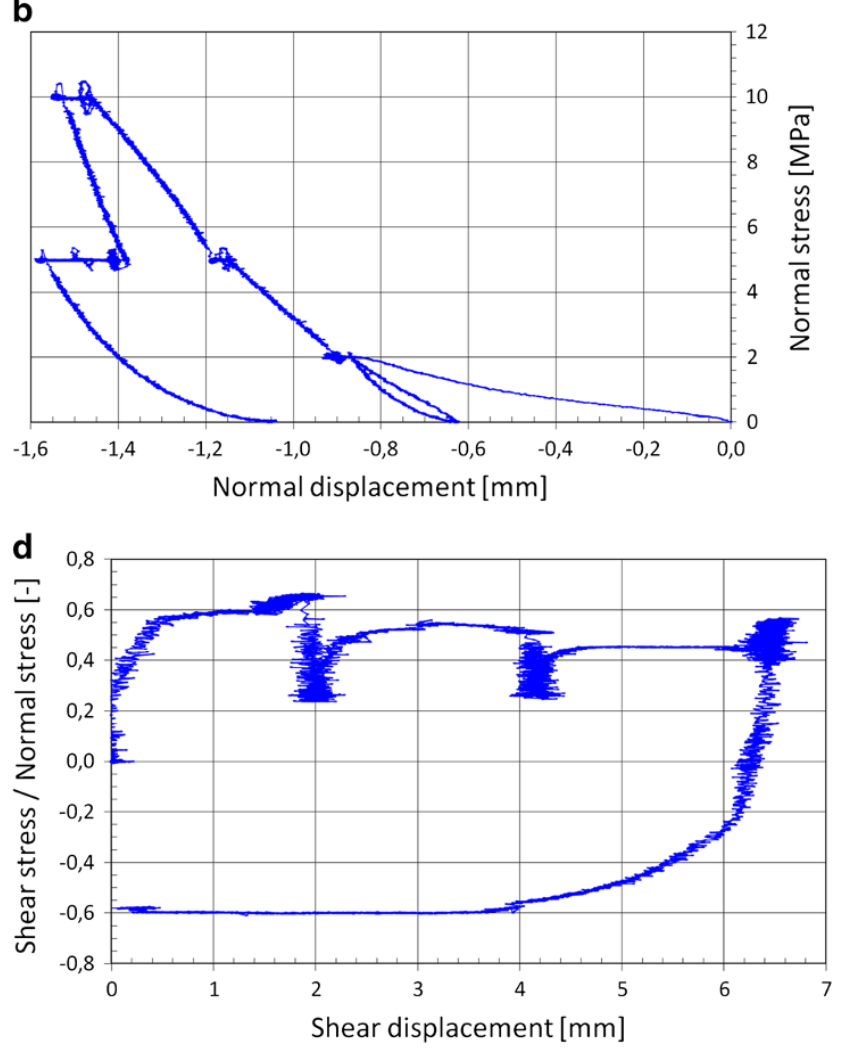

displacement, c normal displacement versus shear displacement, d mobilized friction coefficient versus shear displacement

For the reverse path, only one stage of shearing was performed and the average shear stress was about $3 \mathrm{MPa}$ for a normal stress of $5 \mathrm{MPa}$.

It can be seen in Fig. 3c that there was almost no dilation when shearing occurred in the initial direction; however, for the reverse path a slight dilation was observed at the beginning due to some gouge production.

The mobilized friction rapidly increased to stabilize to a residual level (Fig. 3d). A change in the shearing direction produced a slight decrease in the mobilized friction since the shear stress no longer goes through a peak, a phenomenon that is probably due to abrasion of the surface of the shale specimen.

\section{Shearing with a constant volume (CV test)}

In this test, a dry shale-steel interface was sheared while maintaining a constant volume (zero normal relative displacement), which means that the normal stress was controlled to prevent dilation or contraction of the interface.

Test results are presented in Fig. 4. As in the CNL test, the test began with a normal loading to $2 \mathrm{MPa}$ (Fig. $4 \mathrm{~b}$ ). Subsequently, the normal stress was increased to $5 \mathrm{MPa}$ 

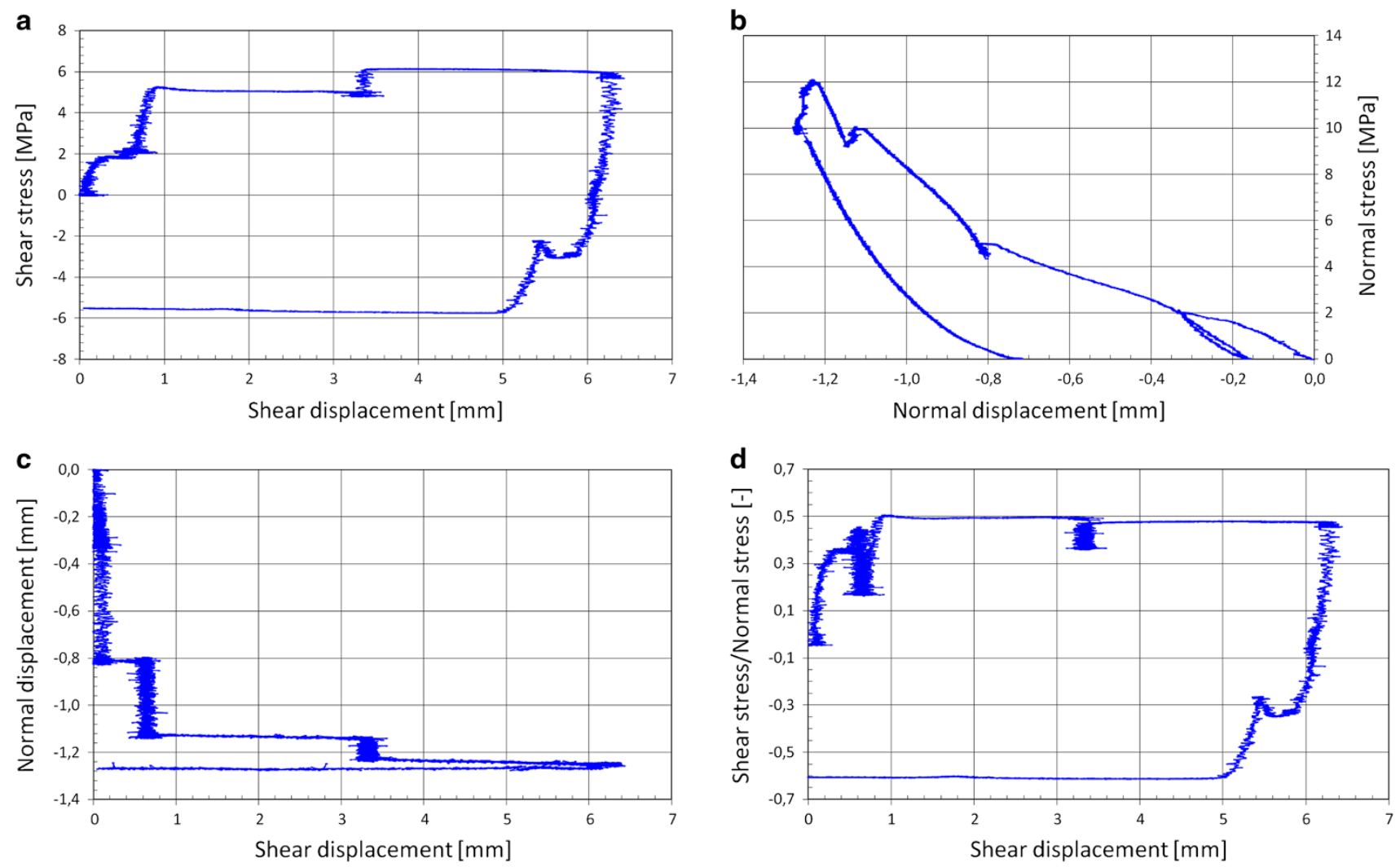

Fig. 4 Shear test TD-CV-18 performed on a dry shale-steel interface under constant volume: a shear stress versus shear displacement, $\mathbf{b}$ normal stress versus normal displacement, $\mathbf{c}$ normal displacement versus shear displacement, $\mathbf{d}$ mobilized friction coefficient versus shear displacement

Fig. 5 Photograph of the dry shale-steel interface after constant volume testing (test TD-CV-18): shale specimen (left hand side); steel plate (right hand side)

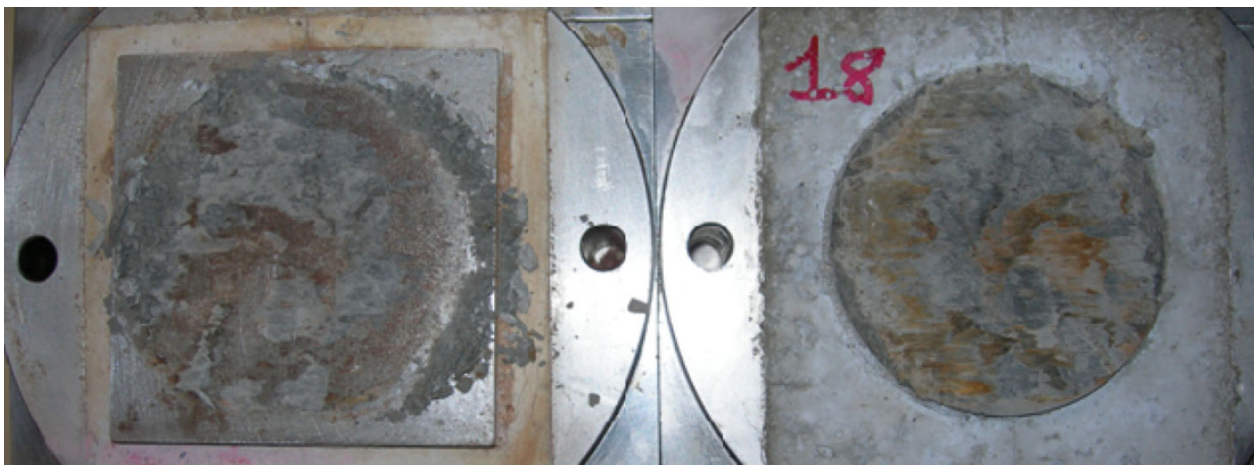

and the shearing started with a constant volume. The test was continued by increasing the normal stress to 10 and then $12 \mathrm{MPa}$.

Figure 4a shows that at the beginning of the test, the shear stress increased with the shear relative displacement to a maximum value and then remained constant (no peak stress). This trend was observed for all three levels of normal stress as well as for the reverse path.

With regard to the normal relative displacement, the maximum value was $1.25 \mathrm{~mm}$ which is slightly less than for the CNL test $(2 \mathrm{~mm})$.

For constant volume tests, when the maximum shear stress was reached, the normal stress decreased (Fig. 4b).
Figure 5 shows the specimen T-CV-18 after a direct shear test at constant volume; the rock surface is damaged as revealed by some noticeable straight scratches. Rock fragments are clearly visible on the steel plate (bottom half boxe).

Direct shear tests on wet shale-steel interface

\section{Shearing at constant normal stress (CNL tests)}

The objective of this test was to characterize the mechanical behavior of the shale-steel interface in the presence of water. In order to compare these results with those 

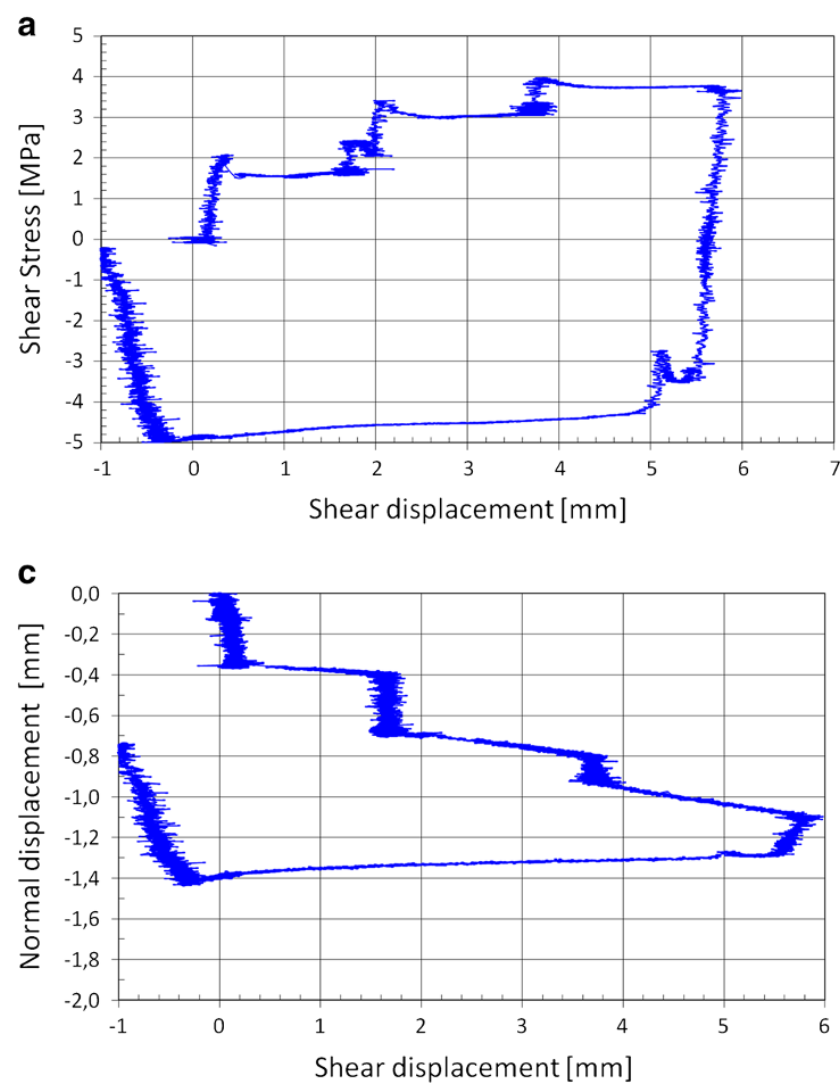

Fig. 6 Shear test TW-CNL-15 performed on a wet shale-steel interface under a constant normal load CNL (5, 10 and $12 \mathrm{MPa}$ ): a shear stress versus shear displacement, b normal stress versus

performed on dry interfaces, all test conditions (normal stress stage and loading rate) were kept the same.

Before shearing the specimens, the swelling of the specimen was characterized. The swelling potential of the specimen was measured by injecting water for 3 days, in several steps (three times per day, 5-10 h apart). At the early stage of testing, an initial normal stress $(0.1 \mathrm{MPa})$ was applied to the specimen and the normal displacement measured.

After 3 days of fresh water injection and swelling measurements, the specimen was sheared. This test was conducted under the same conditions as the previous tests. The normal stress was increased in stages and then the interface was sheared. At the end of the actuator stroke, the specimen was sheared in the opposite direction.

Figure 6 presents the results of the shear test on specimen TW-CNL-15. It was found that the shear stress increased rapidly with the normal stress. At $5 \mathrm{MPa}$ normal stress, the shear stress reached a peak and then decreased slowly. Same trends are observed for the next two levels of normal stress (10 and $12 \mathrm{MPa}$ ). The maximum relative normal displacement was $1.4 \mathrm{~mm}$ for a normal stress of $12 \mathrm{MPa}$. b
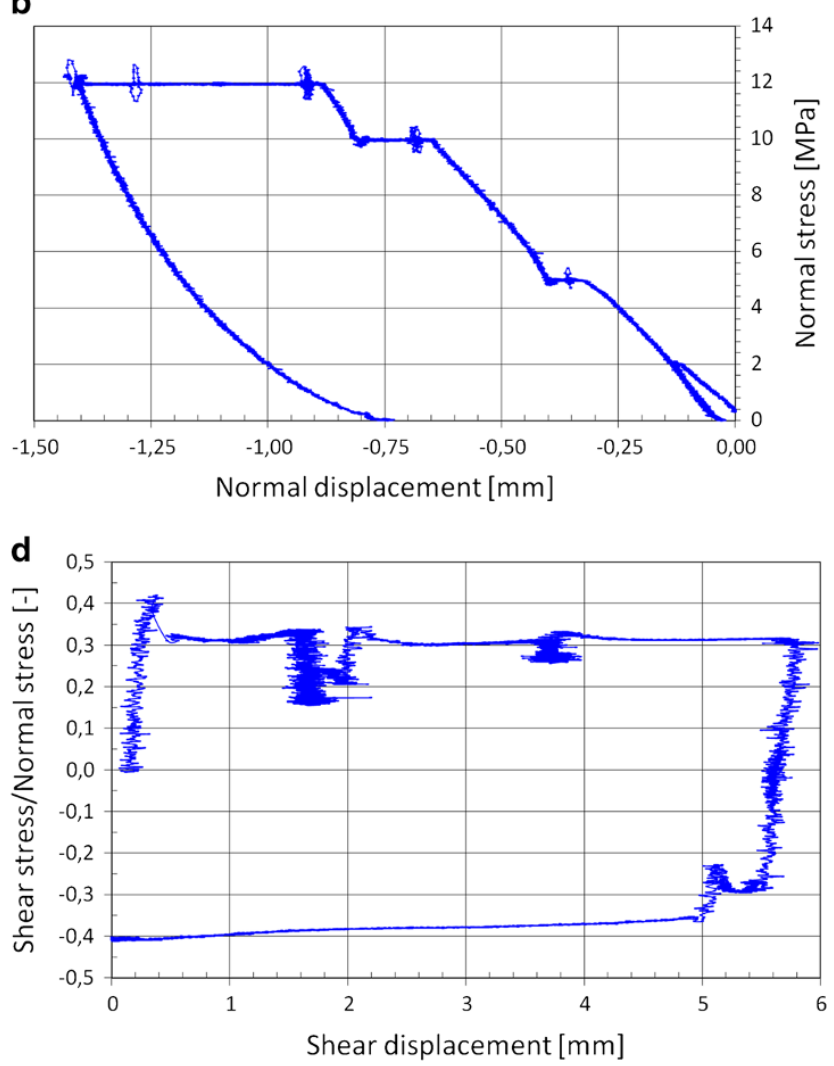

normal displacement, c normal displacement versus shear displacement, $\mathbf{d}$ mobilized friction coefficient versus shear displacement

The friction coefficient of the wet shale-steel interface decreased compared to that of the dry shale-steel interface for normal stresses of 10 and $12 \mathrm{MPa}$ (Fig. 6d). As in the previous tests, the coefficient of friction is independent of normal stress between 10 and $12 \mathrm{MPa}$.

The specimen after testing is shown on Fig. 7. The steel plate is clearly wet, whereas the shale specimen is severely damaged. Because of the humidity, no shearing scratches are noticeable.

\section{Shear constant volume (CV test)}

Shear tests were also conducted at a constant volume on a wet shale-steel interface in the presence of water (resaturated).

As in the previous tests, the swelling and compaction were measured before performing the shear test. Water was injected for at least 3 days prior testing and the swelling of the specimens was measured during the water injection. Figure 8 shows the results of these measurements for specimen TW-VC-20.

At constant volume, the wet shale-steel interface behaves differently from the dry interface. The first difference is in 
Fig. 7 Photograph of the wet shale-steel interface after CNL testing (test TW-CNL-15): shale specimen (left-hand side); steel plate (right-hand side)

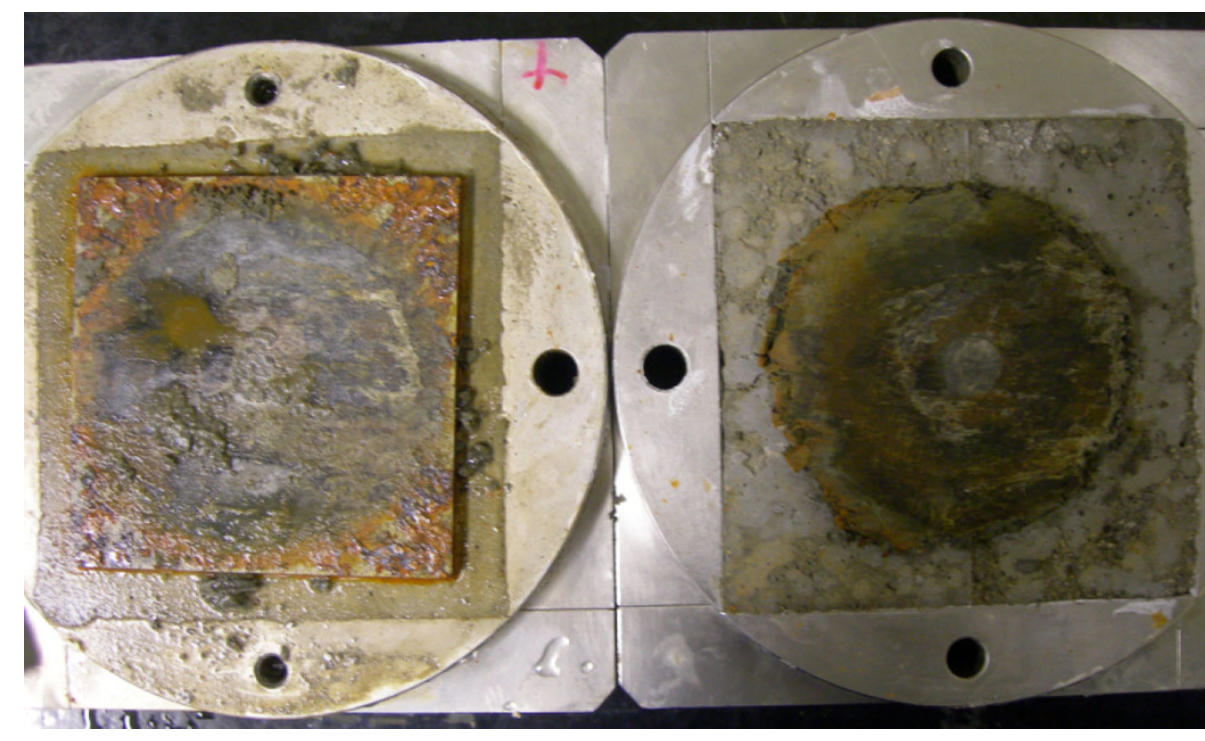

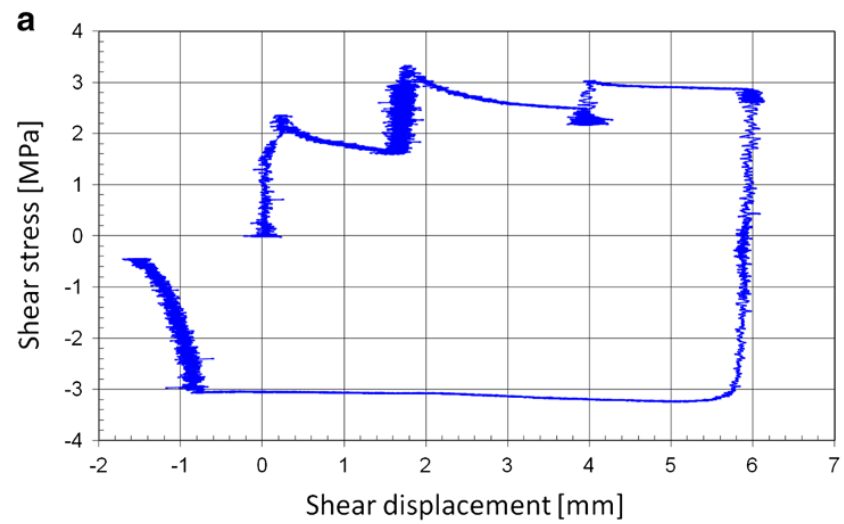

C

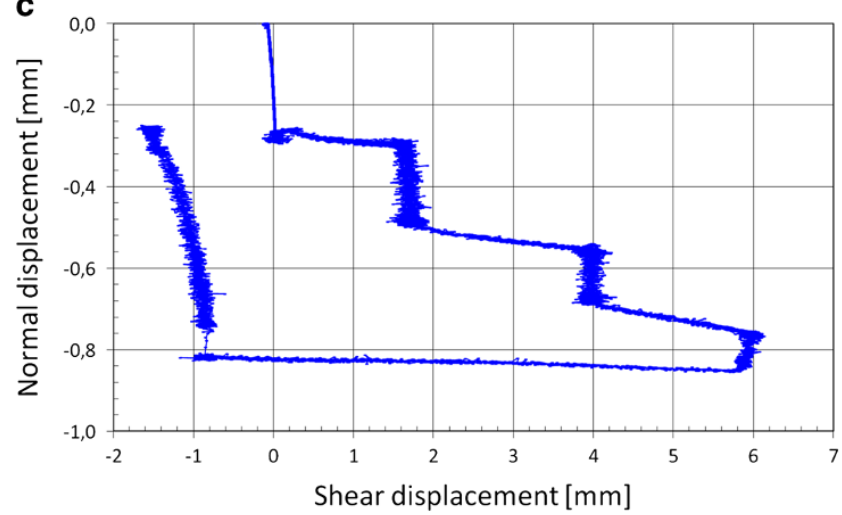

b
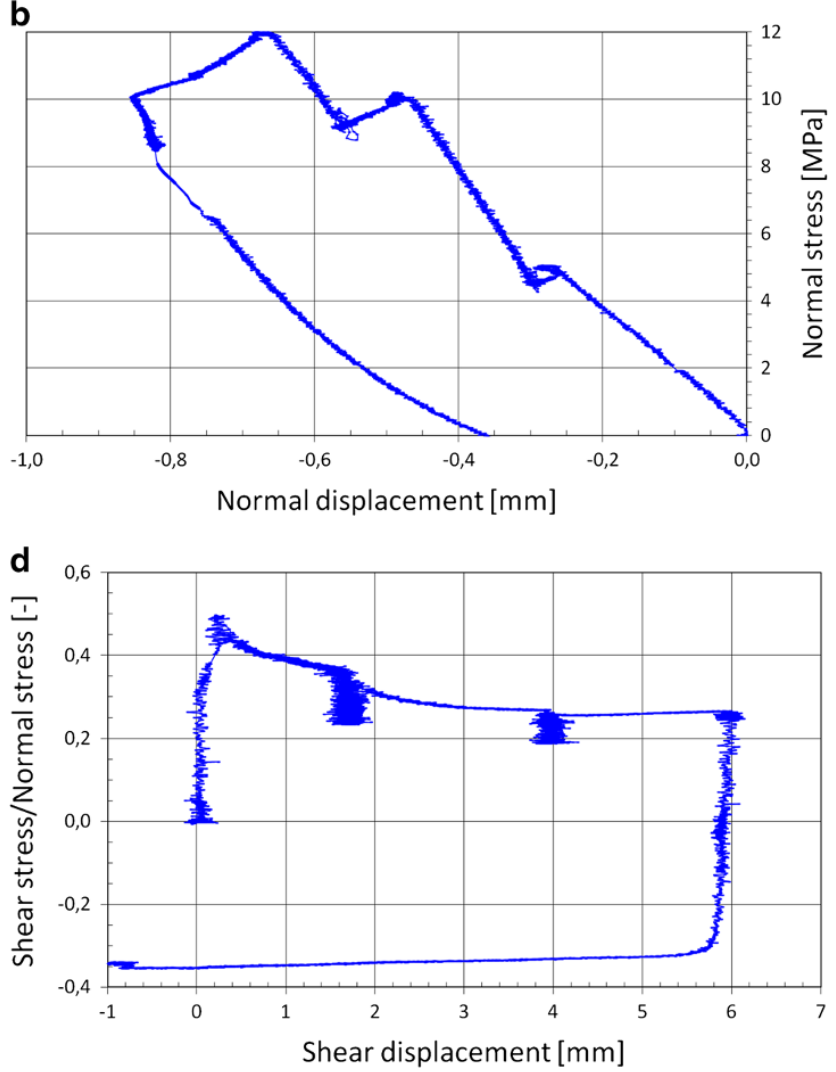

Fig. 8 Shear test TW-CV-20 performed on a wet shale-steel interface under constant volume: a shear stress versus shear displacement, $\mathbf{b}$ normal stress versus normal displacement, $\mathbf{c}$ normal displacement versus shear displacement, $\mathbf{d}$ mobilized friction coefficient versus shear displacement

the evolution of shear stress; for all normal stress levels, the shear stress reaches a peak value and then decreases more significantly (Fig. 8a). The second difference deals with the friction coefficient, which decreases by $40 \%$ (Fig. $8 d$ ). It can be concluded that the degradation of the sample surface in the presence of water is more important than in the dry condition.
Summary and discussion of test results

Using the experimental results, the mechanical parameters of the shale-steel interface were computed. The values are summarized in Tables 3 and 4. Attention is focused on the maximum shear stress and the frictional coefficient. 
Table 3 Results of shear tests performed on a dry shale-steel interface

\begin{tabular}{|c|c|c|c|c|c|c|c|c|c|c|c|c|}
\hline \multirow{2}{*}{$\begin{array}{l}\text { Normal stress } \\
\text { Parameters }\end{array}$} & \multicolumn{3}{|c|}{$2 \mathrm{MPa}$} & \multicolumn{3}{|c|}{$5 \mathrm{MPa}$} & \multicolumn{3}{|c|}{$10 \mathrm{MPa}$} & \multicolumn{3}{|c|}{$12 \mathrm{MPa}$} \\
\hline & $K_{\mathrm{s}}$ & $\tau_{\max }$ & $\tau / \sigma_{\mathrm{n}}$ & $K_{\mathrm{s}}$ & $\tau_{\max }$ & $\tau / \sigma_{\mathrm{n}}$ & $K_{\mathrm{s}}$ & $\tau_{\max }$ & $\tau / \sigma_{\mathrm{n}}$ & $K_{\mathrm{s}}$ & $\tau_{\max }$ & $\tau / \sigma_{\mathrm{n}}$ \\
\hline TD-CNL-08 & 12.5 & 1.0 & 0.50 & 6.9 & 2.0 & 0.38 & 4.8 & 3.8 & 0.36 & - & - & - \\
\hline TD-CNL-10 & - & - & - & - & - & - & 7.6 & 3.9 & 0.36 & - & - & - \\
\hline TD-CNL-12 & 2.0 & 1.1 & 0.57 & 4.0 & 2.5 & 0.53 & - & - & - & 7.5 & 4.7 & 0.45 \\
\hline TD-CNL-14 & - & - & - & 12.4 & 2.1 & 0.38 & 10.1 & 3.4 & 0.34 & 10.6 & 4.4 & 0.36 \\
\hline TD-CNL-16 & - & - & - & 2.0 & 2.3 & 0.52 & 8.8 & 5.3 & 0.55 & 4.2 & 6.6 & 0.56 \\
\hline TD-CV-18 & - & - & - & 6.5 & 1.9 & 0.42 & 12.9 & 5.2 & 0.50 & 14.1 & 6.1 & 0.48 \\
\hline Mean value & 7.2 & 1.0 & 0.53 & 6.4 & 2.2 & 0.44 & 7.8 & 4.1 & 0.40 & 9.1 & 5.4 & 0.45 \\
\hline Standard deviation & \pm 7.4 & \pm 0.1 & \pm 0.04 & \pm 3.9 & \pm 0.2 & \pm 0.07 & \pm 3.0 & \pm 0.9 & \pm 0.09 & \pm 4.2 & \pm 1.0 & \pm 0.08 \\
\hline
\end{tabular}

Table 4 Results of shear tests performed on a wet shale-steel interface

\begin{tabular}{|c|c|c|c|c|c|c|c|c|c|c|c|c|}
\hline \multirow{2}{*}{$\begin{array}{l}\text { Normal stress } \\
\text { Parameters }\end{array}$} & \multicolumn{3}{|c|}{$2 \mathrm{MPa}$} & \multicolumn{3}{|c|}{$5 \mathrm{MPa}$} & \multicolumn{3}{|c|}{$10 \mathrm{MPa}$} & \multicolumn{3}{|c|}{$12 \mathrm{MPa}$} \\
\hline & $k_{\mathrm{s}}$ & $\tau_{\text {pic }}$ & $\tau / \sigma_{\mathrm{n}}$ & $k_{\mathrm{s}}$ & $\tau_{\text {pic }}$ & $\tau / \sigma_{\mathrm{n}}$ & $k_{\mathrm{s}}$ & $\tau_{\text {pic }}$ & $\tau / \sigma_{\mathrm{n}}$ & $k_{\mathrm{s}}$ & $\tau_{\text {pic }}$ & $\tau / \sigma_{\mathrm{n}}$ \\
\hline TW-CNL-09 & 4.1 & 1.6 & 0.28 & 7.4 & 2.9 & 0.29 & 6.1 & 3.7 & 0.32 & - & - & - \\
\hline TW-CNL-11 & - & - & - & - & - & - & 29.0 & 3.5 & 0.33 & - & - & - \\
\hline TW-CNL-13 & - & - & - & 9.5 & 3.0 & 0.40 & 8.0 & 3.2 & 0.32 & 6.1 & 3.9 & 0.33 \\
\hline TW-CNL-15 & - & - & - & 9.4 & 2.1 & 0.42 & 10.1 & 3.4 & 0.34 & 3.5 & 4.0 & 0.33 \\
\hline TW-CV-20 & - & - & - & 11.7 & 2.4 & 0.37 & 8.0 & 3.3 & 0.27 & 4.3 & 3.0 & 0.26 \\
\hline TW-CV-22 & 9.0 & 0.9 & 0.56 & 6.3 & 1.9 & 0.44 & 9.1 & 3.2 & 0.37 & 7.0 & 3.9 & 0.37 \\
\hline Mean value & \pm 6.5 & \pm 1.2 & \pm 0.42 & \pm 8.8 & \pm 2.5 & \pm 0.38 & \pm 11.7 & \pm 3.4 & \pm 0.32 & \pm 5.2 & \pm 3.7 & \pm 0.32 \\
\hline Standard deviation & 3.5 & 0.5 & 0.20 & 2.1 & 0.5 & 0.06 & 8.5 & 0.19 & 0.03 & 1.6 & 0.5 & 0.04 \\
\hline
\end{tabular}

The maximum shear stress is the peak shear stress measured during the shear test. To determine the values of cohesion and the friction coefficient of the interface, the Mohr-Coulomb failure criterion was used for both the wet and dry interface conditions. The Mohr-Coulomb failure criterion implies that the shear strength, which depends on friction coefficient and cohesion, increases linearly with the stress level.

Figures 9 and 10 show the results for the maximum shear stress versus normal stress. As expected, it is found there is no cohesion between the steel plate and the shale specimen in the dry condition. On the other hand, a cohesion of $1.1 \mathrm{MPa}$ was measured in the presence of water and the frictional coefficient also decreased. The corresponding friction coefficient dropped from $24^{\circ}(0.45)$ in the dry condition to $12^{\circ}(0.21)$ in the wet condition.

The mobilized friction coefficients $\left(\tau_{\text {res }} / \sigma_{\mathrm{n}}\right)$ were calculated for all tests; in order to obtain the total friction coefficient, the residual values of shear stress were used. Note that the actual test conditions, either constant normal load (CNL) or constant volume (CV), had no influence on the friction coefficient.

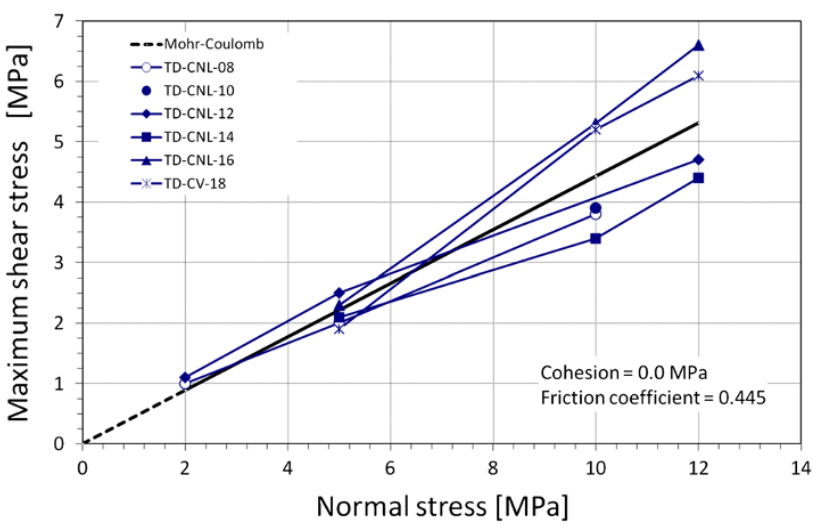

Fig. 9 Maximum shear stress ( $\tau$ peak) versus normal stress for tests on a dry shale-steel interface

The shear stiffness $\left(K_{\mathrm{s}}\right)$ was computed for each test and for each normal stress level (Tables 3,4). The evolution of the shear stiffness is shown to be independent of the testing conditions, the loading path and the normal stress during the test. The dispersion of results does not allow for any clear conclusions to be drawn. 


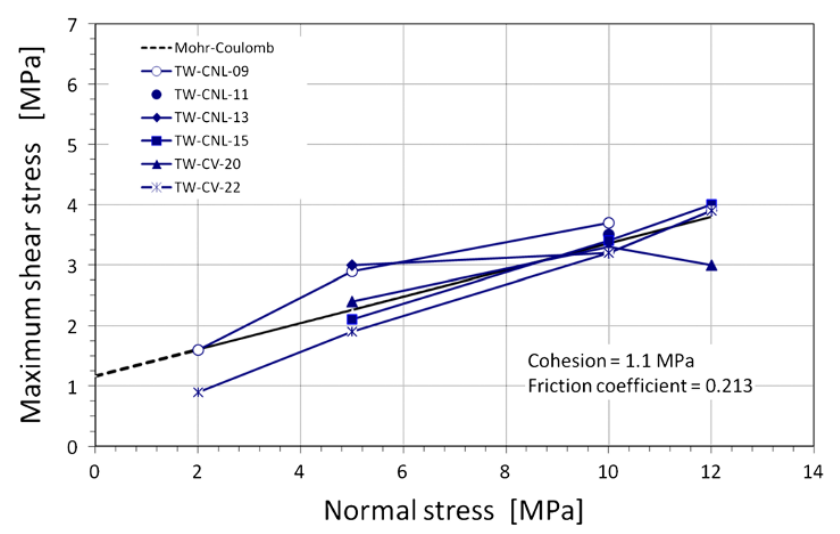

Fig. 10 Maximum shear stress ( $\tau$ peak) versus normal stress for tests on a wet shale-steel interface

\section{Conclusions}

From the results of the 12 shear tests performed on shalesteel interfaces in dry or wet conditions, the following conclusions can be drawn:

- In the shear tests performed with constant normal stress and constant volume, the friction coefficient is independent of normal stress between 5 and $12 \mathrm{MPa}$.

- For the tests performed with constant normal stress, we observed that below $5 \mathrm{MPa}$, the interface sometimes dilates. However, under higher normal stress conditions (10 and $12 \mathrm{MPa}$ ), the interface always tended to contract.

- The presence of fresh water changes the mechanical properties of the interface. The friction coefficient is decreased whereas cohesion is increased. Overall, the shear strength of the interface is significantly less under saturated conditions than in a dry condition.

- For both types of tests (CNL and CV), the values of the coefficient of friction measured in the initial shear direction are more reliable than those obtained during the reverse path.

- The shale-steel interface behavior remains almost isovolumetric during shearing, except during the reversal of the shearing path due to the presence of gouge.

Although in real well bore drilling, the fluid is often a water base mud made up of salted water, it is believed that these conclusions will be useful to estimate the shear strength parameters (friction coefficient and cohesion) of shale-steel interfaces. Indeed, these parameters are significantly lower in saturated conditions (usually found in a reservoir) than those in dry conditions, which are sometimes encountered in the upper section of a borehole.

Knowing the friction coefficient and cohesion parameters makes it possible to perform modeling of the interaction between the host rock and the drilling equipment or casing, when complex cases require such an approach. For instance, the horizontal stresses $\left(\mathrm{Sh}_{\min }\right.$ and $\mathrm{SH}_{\max }$ ) which vary with the depth, will affect directly the shear strength of the rock-equipment interface through the normal stress acting on the interface.

Despite the fact that some caution is needed in using these parameters, while accounting for the scale effects and site conditions, the expectation will be to get a better assessment of the forces and torques (by integration of the local shear stresses over the well depth) that are required to pull out tools of the boreholes when they get stuck or to run casing strings when the borehole is deviated. Therefore, the risk of encountering problems during well drilling could be mitigated.

Acknowledgments The authors wish to thank the French National Radioactive Waste Management Agency (ANDRA) for having financially supported this research study.

Open Access This article is distributed under the terms of the Creative Commons Attribution License which permits any use, distribution, and reproduction in any medium, provided the original author(s) and the source are credited.

\section{References}

Azar JJ (2006) Drilling problems and solutions. Petroleum Engineering Handbook: vol. II Drilling Engineering, Society of Petroleum Engineers

Boulon M (1995) A 3D direct shear device for testing the mechanical behaviour and the hydraulic conductivity of rock joints. Second Int. Conf. on Mechanics of Jointed and Faulted Rock MJFR-2, Vienne, Balkema. Rotterdam, pp 407-413

Buzzi O, Hans J, Boulon M, Deleruyelle F, Besnus F (2007) Hydromechanical study of rock-mortar interfaces. Phys Chem Earth 32:820-831

Cariou S, Dormieux L, Skoczylas F (2009) Swelling of a bentonite plug: a micromechanical approach. In: Eberhardsteiner $\mathbf{J}$ et al (eds) ECCOMAS multidisciplinary jubilee symposium, computational methods in applied sciences. Springer, Berlin, pp 777-781

Castelletto N, Ferronato M, Gambolati G, Janna C, Teatini P (2010) Numerical modeling of rock/casing interaction in radioactivemarker boreholes of the Northern Adriatic Basin, Italy. J SPE Reserv Eval Eng 13(6):906-913

Fabre G, Pellet F (2006) Creep and time dependent damage in argillaceous rocks. Int J Rock Mech Min Sci 43(6):950-960

Fontoura SAB, Inoue N, Martinez IMR, Cogollo C (2012) Rock mechanics aspects of drill bit rock interaction, Harmonising Rock Engineering and the Environment, Proc 12th ISRM Congress, Beijing, China, 2, 2041-2046

Hans J, Boulon M (2003) A new device for investigating the hydromechanical properties of rock joints. Int J Numer Anal Meth Geomech 27:513-548

Jafari MK, Amini Hosseini K, Pellet F, Boulon M, Buzzi O (2003) Evaluation of shear strength of rock joints subjected to cyclic loading. Soil Dynamics Earthquake Eng 23(7):619-630

Lagreca AJ, Miska SZ, Sorem JR (1997) Modeling of acceptable hole curvature for running casing strings: preliminary study, SPE 
Annual Technical Conference and Exhibition, San Antonio, Texas, SPE 38614

Maidla EE, Wojtanowicz AK (1990) Laboratory study of borehole friction factor with a dynamic-filtration apparatus. J SPE Drill Eng 5(3):247-255

Mason CJ, Williams LG, Murray GN (2000) Reinventing the wheelreducing friction in high-angle wells, SPE Annual Technical Conference and Exhibition, Dallas, Texas

Mirhaj SA, Kaarstad E, Aadnoy BS (2011) Improvements of torqueand-drag modeling in long-reach wells. Modern Appl Sci 5(5): $10-28$

Padma Raju B, Kumara Swamy M (2012) Effect of tool material in friction drilling: a case study. Int J Mech Prod Eng Res Dev 2(4):51-60
Pellet FL, Fabre G (2007) Damage evaluation with P-wave velocity measurements during uniaxial compression tests on argillaceous rocks, International Journal of Geomechanics. Am Soc Civil Eng (ASCE) 7(6):431-436

Pellet FL, Keshavarz M, Boulon M (2013) Influence of humidity conditions on shear strength of clay rock discontinuities. Eng Geol 157:33-38

Rojas JC, Clark DE, Zhang J (2006) Stressed shale drilling strategywater activity design improves drilling performance, society of petroleum engineers, SPE Annual Technical Conference and Exhibition, San Antonio, Texas

Sanchez F, Al-Harthy MH (2011) Risk analysis: casing-while-drilling (CwD) and modeling approach. J Petrol Sci Eng 78(1):1-5 